\title{
Low production of reactive oxygen species in granulocytes is associated with organ damage in systemic lupus erythematosus
}

\author{
Anders A Bengtsson ${ }^{1}$, Åsa Pettersson², Stina Wichert ${ }^{3}$, Birgitta Gullstrand ${ }^{4}$, Markus Hansson ${ }^{3}$, \\ Thomas Hellmark ${ }^{2}$ and Åsa CM Johansson ${ }^{3,5^{*}}$
}

\begin{abstract}
Introduction: Polymorphonuclear leukocytes (PMN) are main effector cells in the acute immune response. While the specific role of PMN in systemic lupus erythematosus (SLE) and autoimmunity is still unclear, their importance in chronic inflammation is gaining more attention. Here we investigate aspects of function, bone marrow release and activation of PMN in patients with SLE.

Methods: The following PMN functions and subsets were evaluated using flow cytometry; (a) production of reactive oxygen species (ROS) after ex vivo stimulation with phorbol 12-myristate 13-acetate (PMA) or Escherichia coli (E. coli); (b) capacity to phagocytose antibody-coated necrotic cell material; (c) PMN recently released from bone marrow, defined as percentage of CD10-D16 ${ }^{\text {low }}$ in peripheral blood, and (d) PMN activation markers; CD11b, CD62L and $C 5 a R$.

Results: SLE patients ( $n=92)$ showed lower ROS production compared with healthy controls $(n=38)$ after activation ex vivo. The ROS production was not associated with corticosteroid dose or other immunotherapies. PMA induced ROS production was significantly reduced in patients with severe disease. In contrast, neither ROS levels after E. coli activation, nor the capacity to phagocytose were associated with disease severity. This suggests that decreased ROS production after PMA activation is a sign of changed PMN behaviour rather than generally impaired functions. The $\mathrm{CD}_{10} \mathrm{CD}^{-} 6^{\text {low }}$ phenotype constitute $2 \%$ of PMN in peripheral blood of SLE patients compared with $6.4 \%$ in controls, indicating a decreased release of PMN from the bone marrow in SLE. A decreased expression of C5aR on PMN was observed in SLE patients, pointing towards in vivo activation.

Conclusions: Our results indicate that PMN from SLE patients have altered function, are partly activated and are released abnormally from bone marrow. The association between low ROS formation in PMN and disease severity is consistent with findings in other autoimmune diseases and might be considered as a risk factor.
\end{abstract}

\section{Introduction}

Systemic lupus erythematosus (SLE) is a chronic systemic autoimmune disease affecting several organ systems such as skin, joints, kidneys and central nervous system. Many of the disease manifestations in SLE are related to immune complexes, consisting of autoantibodies and remnants of apoptotic cells [1]. Apoptotic cells are thought to be a

\footnotetext{
* Correspondence: asa.johansson@med.lu.se

${ }^{3}$ Department of Haematology, Lund University, BMC B13, 22184 Lund, Sweden

${ }^{5} \mathrm{Clinical}$ Immunology and Transfusion Medicine, University and Regional Laboratories Region Skåne, 22185 Lund, Sweden

Full list of author information is available at the end of the article
}

major source of auto-antigens in SLE, partly because of impaired clearance [2,3]. Another potential antigen source is the neutrophil extracellular traps (NETs) that consist of chromatin and antimicrobial enzymes released from neutrophils to trap and kill pathogens. Serum from some SLE patients have a reduced ability to degrade NETs $[4,5]$.

Polymorphonuclear leukocytes (PMN), such as neutrophils, are produced in the bone marrow and released to circulation. During acute inflammation an increased mobilization of neutrophils from the bone marrow occurs, which can be observed as increased percentage of $\mathrm{CD} 10^{-} \mathrm{CD} 16^{\text {low }}$ neutrophils in peripheral blood $[6,7]$. The role of PMN in chronic inflammation and autoimmunity 
is coming into focus, and neutrophils have been suggested to be the primary mediators of end organ-damage responding to deposited immune complexes [8,9]. PMN are recruited to inflammatory sites, and activated by proinflammatory mediators like complement factors, cytokines and chemokines. Upon activation the expression of various surface proteins changes; for example, C5aR and CD62L are down regulated whereas an increase in CD11b expression is observed [10,11]. In addition to the changing expression of surface proteins, activated PMN are primed to release granules and produce reactive oxygen species (ROS) by the nicotinamide adenine dinucleotide phosphateoxidase (NADPH) complex [12]. ROS are major effector molecules in inflammatory processes and tightly linked to NETs formation. During the last decade, an increasing amount of data support a T-cell regulating role for monocyte and PMN-produced ROS [13-16]. Furthermore, the association of SLE to polymorphism in NCF2, encoding a protein in the NADPH oxidase complex, adds support for the importance of ROS in this disease [17]. Of note, patients with chronic granulomatous disease, lacking a functional NADPH oxidase complex, show autoimmune features such as high levels of immunoglobulins and autoantibodies, as well as an increased risk of Crohn's disease and discoid lupus $[18,19]$.

This study aims at characterizing PMN from SLE patients (SLE-PMN), in regard to function, bone marrow release and activation to gain knowledge of the role of PMN in SLE and autoimmunity.

\section{Methods}

\section{Patients and controls}

SLE patients $(n=107)$ were recruited to the study, when coming to their scheduled visit at the Department of Rheumatology, Skåne University Hospital, Lund, Sweden. All patients fulfilled at least four American College of Rheumatology classification criteria for SLE [20]. Disease activity was assessed using the systemic lupus erythematosus disease activity index 2000 (SLEDAI-2 K) [21], and organ damage was evaluated according to the Systemic

Table 1 Patients characteristics and demographics

\begin{tabular}{|c|c|c|c|}
\hline & $\begin{array}{l}\text { All patients } \\
(\mathrm{n}=92)\end{array}$ & $\begin{array}{c}\text { No organ damage } \\
\text { SLICC/ACR-DI }=0(n=42)\end{array}$ & $\begin{array}{c}\text { Organ damage } \\
\text { SLICC/ACR-DI } \geq 1 \quad(n=50)\end{array}$ \\
\hline Age, median (range) years & $48(22$ to 84$)$ & $43(22$ to 79$)$ & $60(24$ to 84$)$ \\
\hline Female gender, $\mathrm{n}(\%)$ & $81(88 \%)$ & $37(88 \%)$ & $44(88 \%)$ \\
\hline Disease duration, median (range) years & 14 (0 to 51$)$ & 9 (0 to 29) & 19 (0 to 51$)$ \\
\hline SLEDAl, median (range) & $2(0$ to 16$)$ & $2(0$ to 16$)$ & $1(0$ to 13$)$ \\
\hline SLICC/ACR-DI median (range) & $1(0$ to 8$)$ & 0 & $2(1$ to 8$)$ \\
\hline PMN $10^{9} / \mathrm{L}$ median (range) & $4.0(<0.1$ to 11$)$ & $3.6(1.4$ to 9.8$)$ & $4.7(<0.1$ to 11$)$ \\
\hline \multicolumn{4}{|l|}{ Disease manifestations at time of sampling, $n$} \\
\hline Lupus headache & 1 & 0 & 1 \\
\hline Arthritis & 10 & 5 & 5 \\
\hline Kidney involvement (urinary cast, hematuria, proteinuria, or pyuria) & 6 & 3 & 3 \\
\hline Rash & 4 & 2 & 2 \\
\hline Alopecia & 2 & 1 & 1 \\
\hline Low complement (C3 or C4) & 36 & 21 & 15 \\
\hline Anti-double stranded DNA antibodies & 18 & 10 & 8 \\
\hline Leukopenia & 7 & 4 & 3 \\
\hline \multicolumn{4}{|l|}{ Treatment } \\
\hline Prednisone, \% (median dose of treated patients) & $53(5 \mathrm{mg})$ & $60(5 \mathrm{mg})$ & 50 (6.25 mg) \\
\hline Hydroxychloroquine, \% (n) & $59(54)$ & $69(29)$ & $50(25)$ \\
\hline Chloroquine phosphate, \% (n) & $2(2)$ & $2(1)$ & $2(1)$ \\
\hline Azathioprine, \% (n) & $24(22)$ & $29(12)$ & $20(10)$ \\
\hline Mycophenolate mofetil\%, (n) & $12(11)$ & $14(6)$ & $10(5)$ \\
\hline Rituximab, \% (n) & $2(2)$ & $0(0)$ & $4(2)$ \\
\hline Methotrexates, \% (n) & $4(4)$ & $5(2)$ & $4(2)$ \\
\hline Cyclosporine A, \% (n) & $2(2)$ & $0(0)$ & $4(2)$ \\
\hline
\end{tabular}

SLICC/ACR-DI, Systemic Lupus International Collaborative Clinics/American College of Rheumatology (ACR) damage index; SLEDAl-2 K, Systemic lupus erythematosus disease activity index 2000; PMN, polymorphonuclear leukocytes. 
Lupus International Collaborative Clinics/American College of Rheumatology damage index (SLICC/ACR-DI) [22]. Demographic and clinical characteristics are shown in Table 1. Healthy blood donors $(n=38$, Blood centre in Lund) and healthy volunteers $(n=15)$ were recruited as controls; ages 18 to 65 years. Complement proteins and autoantibodies were measured using routine analyses (Clinical Immunology and Transfusion Medicine, University and Regional laboratories, Region Skåne, Lund Sweden). The study was approved by the Regional Ethics Review Board at Lund University (file number LU 2010-708) and informed consent was obtained from all participants.

\section{Oxidative burst and expression of surface markers}

ROS production in peripheral blood PMN was investigated using the PhagoBurst assay, Glycotope Biotechnology, $\mathrm{GmBH}$, Germany, according to the manufacturer's protocol after activation with phorbol 12-myristate 13-acetate (PMA) or opsonised Escherichia coli (E. coli), and analysed using flow cytometry. At least 15,000 PMN were analysed based on forward and side scatter properties. No patient with ROS deficiency was observed.

ROS formation in peripheral blood PMN was also quantified by oxidation of 2,7-dichlorofluorescein-diacetate (DCFH-DA, Sigma-Aldrich ${ }^{\circ}$, St. Louis, MO, USA), as previously described [23]. As stimuli PMA and E. coli from the PhagoBurst kit or Staphylococcus aureus (ATCC 25923, 1 leukocyte: 2,000 bacterial cells) and Pseudomonas aeruginosa (ATCC 27853, 1 leukocyte: 200 bacterial cells) were used. S. aureus and $P$. aeruginosa were grown in liquid Tryptic Soy Broth (TSB) medium overnight at $37^{\circ} \mathrm{C}$ and killed by heat $\left(60^{\circ} \mathrm{C}\right)$ for $2 \mathrm{~h}$. To confirm bacterial inactivation a sample was inoculated in TSB and kept for $48 \mathrm{~h}$. The bacteria were centrifuged and re-suspended in $0.8 \%$ saline. Optical density was adjusted to $24 \times 10^{8}$ colony forming units/mL by comparing turbidity to a McFarland scale number $8 \mathrm{BaSO}_{4}$ standard solution. DCFH-DA was added to heparinised whole blood before the various stimuli, and then the samples were incubated in a $37^{\circ} \mathrm{C}$ water bath for 30 minutes. Cells were analysed using flow cytometry.

The expression of selected surface markers on PMN was analysed using flow cytometry. Briefly, peripheral blood was lysed using $0.84 \%$ ammonium chloride. The remaining leukocytes were stained for surface expression of CD14 (to exclude monocytes), CD10, CD11b, CD16, CD62L, and C5aR (CD88) (BD Bioscience San Jose, CA, USA). For flow cytometry analysis a FACSCanto II and the DIVA software (Becton Dickinson, BD, New York, NY, USA) were used.

\section{Cell separation and phagocytosis of antibody-coated necrotic cell material by PMN}

PMN and peripheral blood mononuclear cells were isolated from heparinised blood of SLE patients by density gradient centrifugation on Polymorphprep ${ }^{\mathrm{Tm}}$ (Axis-Shield
Poc AS, Norway). To obtain necrotic cell material, mononuclear cells were incubated for 10 minutes at $70^{\circ} \mathrm{C}$ and stained with propidium iodide (BD Bioscience). The propidium iodide-labelled necrotic cell material $\left(4.5 \times 10^{5}\right.$ cells $)$ was then incubated with or without an anti-nucleosome antibody (clone PL2-3; gift from Marc Monestier, Temple University, Philadelphia, USA) at room temperature for 20 minutes. Normal human serum was used as the negative control. The autologous PMN were stained with antiCD45-FITC (BD Bioscience), and then added to the necrotic cell material, at a concentration of $1.0 \times 10^{6}$ cells $/ \mathrm{mL}$ in a total volume of $300 \mu \mathrm{L}$, followed by incubation at $37^{\circ} \mathrm{C}$ for 15 minutes. Cells were washed with phosphatebuffered saline $\mathrm{pH} 7.2$ containing $0.1 \%$ human serum albumin (Sigma-Aldrich, St. Louis, MO, USA) before analysis by flow cytometry.

\section{Statistical analysis}

Correlations were determined by Spearman's correlation test. The Mann-Whitney $U$-test was used for two-group comparisons and Kruskal-Wallis test with Dunn's multiple comparison test was used for three-group comparisons. All $P$-values were considered significant at $P<0.05$.

\section{Results}

\section{Decreased production of ROS in SLE-PMN}

Phagocyte-produced ROS are important effector molecules in the defence against microbes, and could also be involved in the regulation of the adaptive immune system [15]. To evaluate PMN function in SLE, we decided to investigate intracellular ROS production. PMN in peripheral whole blood from SLE patients $(n=92$, Table 1$)$ and healthy controls $(n=38)$, were stimulated with either the protein kinase $\mathrm{C}$ activator, PMA, or with opsonised E. coli. SLE-PMN showed a decreased capacity to produce ROS ex vivo after activation with both PMA $(P<0.0001)$ and $E$. $\operatorname{coli}(P=0.0002)$ (Figure 1$)$. The decreased amount of ROS produced by SLE-PMN was not associated with the dose of prednisone or hydroxychloroquine treatment (Figure 2A and B) or other immune suppressive drugs listed in Table 1 (not shown). Perazzio et al. have previously shown an increased ROS production in SLE-PMN after in vitro activation with $S$. aureus or $P$. aeruginosa using DCFH-DA as fluorochrome [23]. To evaluate whether this discrepancy was due to experimental procedure or differences in patient population, patients $(n=15)$ and controls $(n=15)$ were analysed in parallel with both methods, using $S$. aureus, P. aeruginosa, PMA and E. coli as stimuli. Similar findings where observed between the two methods (Table 2). SLE-PMN showed a decreased intracellular ROS formation after PMA activation compared with controls (PhagoBurst test: $P=0.0394$ and DCFH-DA: $P=$ 0.0146) whereas no significant difference was observed with the other stimuli (not shown). The decreased ROS 


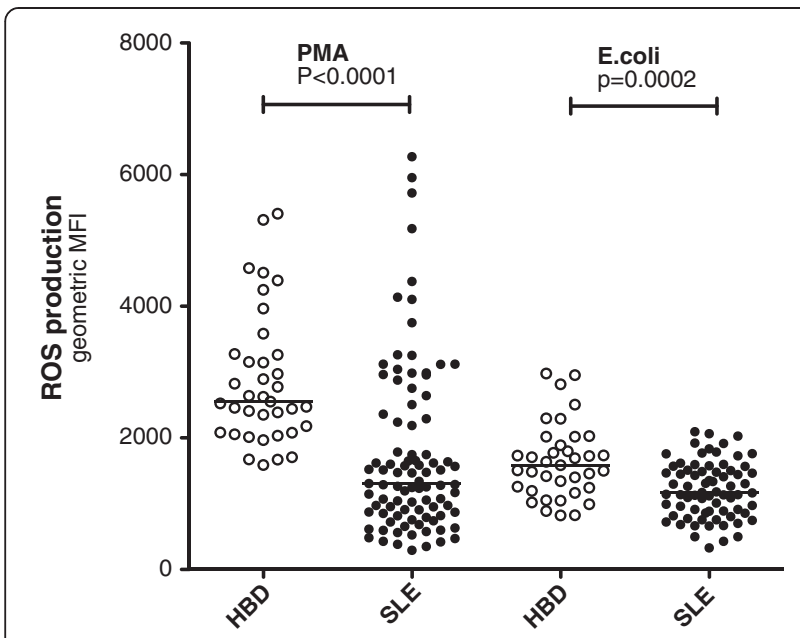

Figure 1 Polymorphonuclear leukocytes (PMN) from patients with systemic lupus erythematosus (SLE) produced fewer reactive oxygen species (ROS) than PMN from healthy blood donors. The capacities of PMN from healthy blood donors (HBD), $n=38$, and SLE patients, $n=92$, to produce ROS upon activation with phorbol

12-myristate 13-acetate or opsonised $E$. coli were investigated using flow cytometry. The amount of ROS produced is shown as geometric mean fluorescence intensity (geo mean fluorescence, MFI). The two-sided Mann-Whitney test was used to calculate the level of significance. The horizontal lines represent the median value of each dataset

production in our examined SLE cohort after PMA activation was consistent using both methods in contrast to the findings of Perazzio et al., suggesting differences in patient populations.

\section{Organ damage was associated with low ROS production in SLE-PMN}

The severity of autoimmune diseases has previously been associated with decreased ROS production [24-26]. Hence, to study if the severity of SLE was associated with changes in ROS production, the patients were divided in two groups based on the presence of organ damage or not according to SLICC/ACR-DI (Table 1). PMN from patients with SLICC/ACR-DI $\geq 1$ had decreased ROS production, compared with patients without organ damage (Figure 3A), when activated with PMA $(P=0.0022)$. No difference was seen after activation with $E$. coli (not shown). Patients with organ damage were in general older than patients without (Table 1), however, the age of the patients was not correlated with PMA-induced oxidative burst in PMN (not shown).

Next, we investigated if disease activity, at the time point of sampling, was associated with ROS production. The patients were divided into three groups based on the SLEDAI-2 K [21]: (1) no activity, (2) laboratory parameters only, such as low complement and anti-double stranded DNA antibodies; and (3) clinical manifestations, for example, nephritis, rash and arthritis. No association between

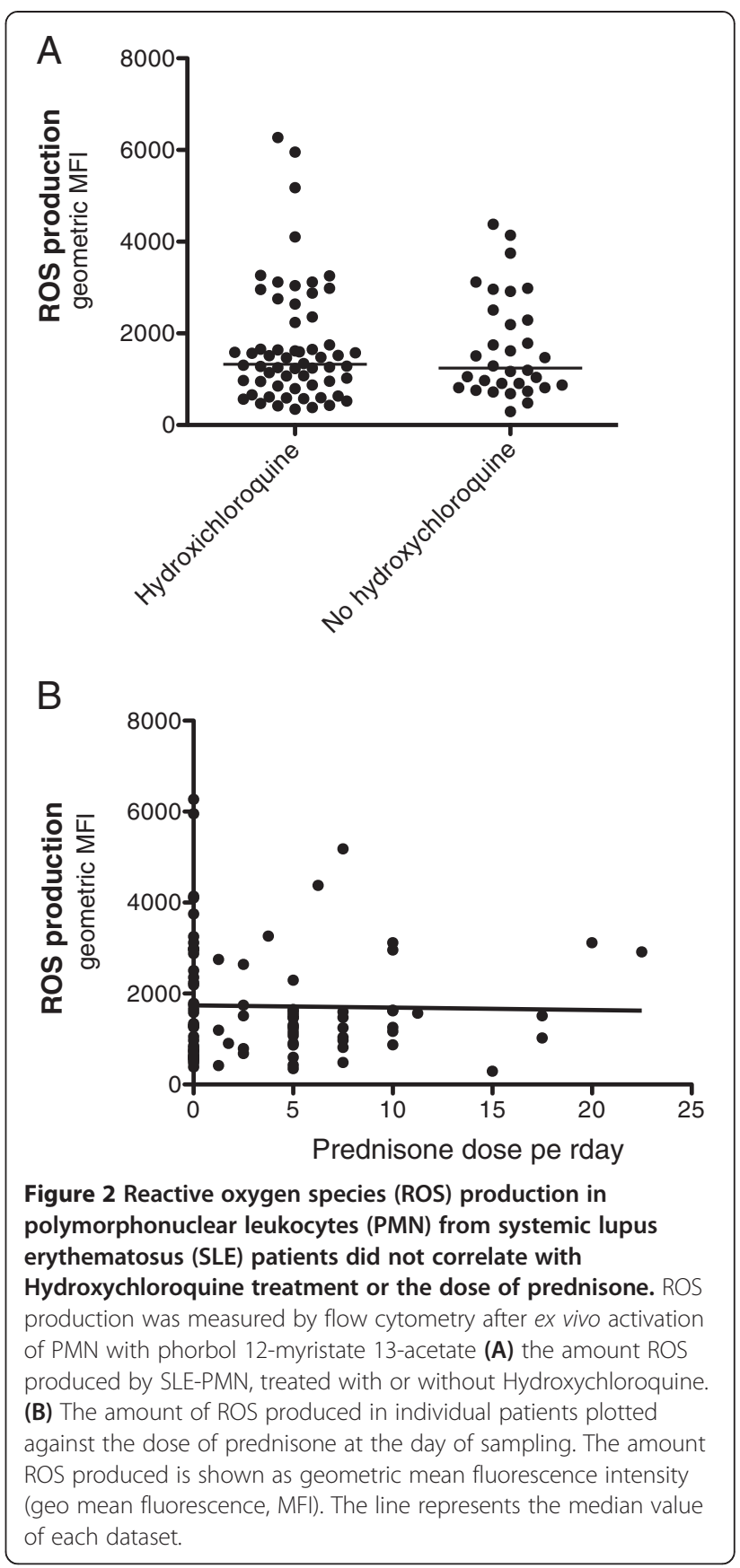

ROS production and disease activity $(P=0.0654)$ was observed (Figure 3B).

Phagocytosis of antibody-coated microbes and foreign material precedes ROS production in PMN. To evaluate further the function of PMN in SLE, in particular in patients with organ damage, the phagocytosis capacity was investigated in 40 out of the 92 patients. Antibody-coated necrotic cells were chosen as stimuli for phagocytosis to relate to lupus erythematosus cells, for example, PMN containing phagocytosed antibody-coated dead cell materials, a phenomenon almost pathognomonic for SLE. No 
Table 2 Comparisons between the PhagoBurst and the DCFH-DA assay

\begin{tabular}{lccc}
\hline & \multicolumn{2}{c}{ Relative reactive oxygen species formation in SLE patients as\% of formation in healthy controls } & DCFH-DA \\
\cline { 2 - 3 } Stimuli & PhagoBurst & $76 \pm 6.2$ & 0.6783 \\
\hline PMA & $68 \pm 7.7$ & $103 \pm 13$ & 0.1775 \\
E. coli & $84 \pm 13$ & $102 \pm 6.3$ & 0.2716 \\
S. aureus & $92 \pm 8.7$ & $97 \pm 14$ & 0.5897 \\
P. aeruginosa & $88 \pm 12$ &
\end{tabular}

Comparisons of the PhagoBurst assay with the dichlorodihydrofluorescein-diacetate (DCFH-DA) assay according to Perazzio et al. [23]. No significant differences between the methods were observed. Polymorphonuclear leukocytes (PMN) from systemic lupus erythematosus (SLE) patients ( $=15)$ and healthy controls $(n=15)$ were analysed in parallel with both methods using phorbol 12-myristate 13-acetate (PMA), E. coli, S. aureus or P. aeruginosa as stimuli. ROS formation was defined as geometric mean fluorescence intensity. Samples from each individual patient were divided by the mean value of the controls to gain the relative ROS formation in SLE-PMN as\% of ROS produced in healthy controls. Values represent mean \pm standard error of the mean. The two-sided Mann-Whitney test was used to calculate the level of significance.

differences were observed between patients with $(\mathrm{n}=$ 25; SLICC/ACR-DI $\geq 1$ ), compared to patients without organ damage $(n=15$; SLICC/ACR-DI $=0)$, further suggesting that the decreased ROS production in patients with severe disease is not due to a general unresponsiveness (Figure 3C). No associations between disease activity based on SLEDAI-2 K and the ability to phagocytose were observed (not shown).

\section{Low numbers of $\mathrm{CD} 10^{-} \mathrm{CD} 16^{\text {low }}$ SLE-PMN}

During acute inflammation, an increased percentage of $\mathrm{CD} 10^{-} \mathrm{CD} 16^{\text {low }}$ neutrophils in peripheral blood are thought to reflect an increased mobilization of cells from bone marrow [6,7]. To study the frequency of newly released $\mathrm{CD} 10^{-} \mathrm{CD} 16^{\text {low }} \mathrm{PMN}$ in peripheral blood, samples from 73 SLE patients, and 27 healthy controls were analysed by flow cytometry. SLE patients showed lower percentages of $\mathrm{CD} 10^{-} \mathrm{CD} 16^{\text {low }} \mathrm{PMN}$ (Figure 4), compared with healthy controls $(P<0.0001)$. Hence, the SLE-PMN were to a high extent $\mathrm{CD} 10^{+} \mathrm{CD} 16^{+}$compared with controls $(P<0.0001)$, which is consistent with a decreased release of PMN from the bone marrow.

To characterize the activation status of PMN in peripheral blood the expression of C5aR, CD11b and CD62L was investigated. SLE-PMN were to a lesser extent C5aR positive $(P<0.0001)$, and the positive cells expressed less C5aR $(P<0.0001)$ (Table 3). No differences in the expression of CD11b or CD62L were observed (Table 3), indicating that the cells were only partly activated. C5aR expression and percentage of $\mathrm{CD} 10^{-} \mathrm{CD} 16^{\text {low }} \mathrm{PMN}$ were not correlated with SLICC/ACR-DI or SLEDAI-2 K (not shown).

\section{Discussion}

PMN were characterized with respect to function, bone marrow release and activation to study their role in SLE, yielding evidence for decreased ROS production in SLE and autoimmunity. Our data support that SLE-PMN have decreased capacity to produce ROS ex vivo. The association with disease severity, defined as organ damage, further strengthened our finding. Low ROS production has been associated with disease severity of other autoimmune conditions, including Behcet's disease [24], Guillain-Barre syndrome [25] and multiple sclerosis [26], and might be a common denominator important in the pathogenesis of autoimmunity.

Interestingly, PMA-induced ROS production was significantly reduced in patients with severe disease. However, neither ROS production after $E$. coli activation nor phagocytosis of necrotic cell material were associated with organ damage, suggesting that decreased ROS levels after PMA activation is not a sign of impaired PMN functions in general but rather a sign for changed PMN behaviour. While the activation and control of the NADPH oxidase in neutrophils (NOX2) is incompletely understood, it seems that different agonists encountered by the neutrophils engage various combinations of kinases and thereby affect the degree of activity of the NADPH complex, and in the end the amount of ROS produced [27]. To some extent, this could explain why ROS production after $E$. coli activation was not associated with organ damage; $E$. coli induced a lower degree of phosphorylation of the NADPH complex regulating subunits compared with PMA that is known to push the NADPH complex to its maximal capacity [27]. Hence, PMA revealed altered behaviour in PMN from patients with organ damage.

While no association between ROS levels and current disease activity was observed, most patients were in remission or had low to moderate activity based on SLEDAI$2 \mathrm{~K}$ (Table 1). An association between disease activity and ROS production could not be excluded based on the available data. The literature is not concurrent regarding ROS production by SLE-PMN [23,28,29]. For example, Perazzio et al. have shown that neutrophils from SLE patients have an increased capacity to produce ROS, and they did not find any correlation with organ damage or disease activity [23]. This discrepancy does not reflect the use of different methods, as we observed comparable results with both methods. A more likely explanation is variations in patient cohorts. We have observed an association between decreased ROS formation and disease severity, and a tendency towards increased ROS formation in SLE-PMN in patients with clinical symptoms. Most patients in our 

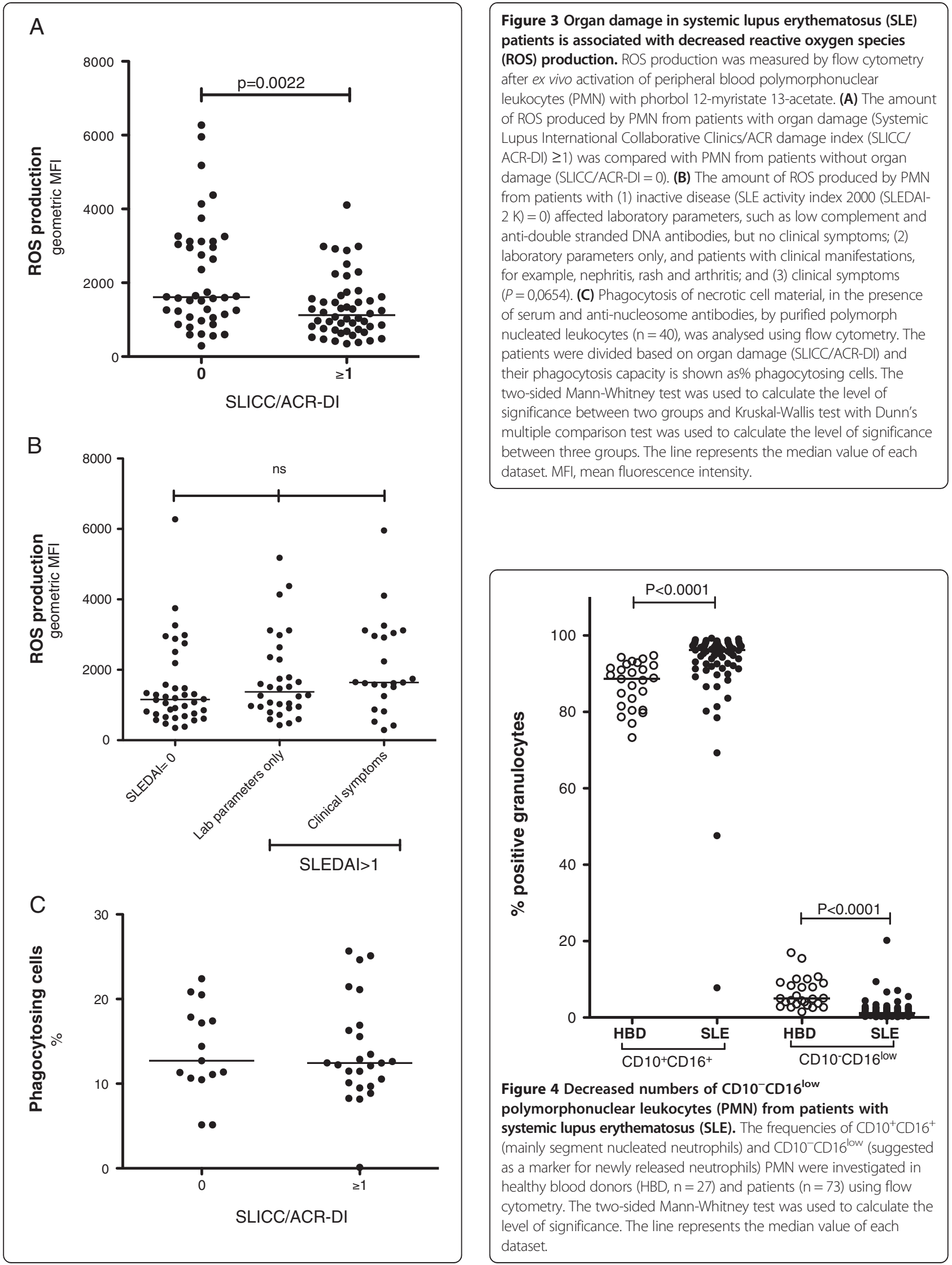
Table 3 Decreased expression of C5aR (CD88) on polymorphonuclear leukocytes (PMN) from patients with systemic lupus erythematosus (SLE)

\begin{tabular}{lccc}
\hline Phenotype & Healthy blood donors & SLE patients & $\boldsymbol{P}$-value \\
\hline CD88, \% & $92 \pm 3.8$ & $77 \pm 1$ & $\leq 0.0001$ \\
CD88, geoMFI & $466 \pm 24$ & $285 \pm 4$ & $\leq 0.0001$ \\
CD62L, \% & $98 \pm 0.3$ & $98 \pm 0.2$ & ns \\
CD62L, geoMFI & $1180 \pm 64$ & $1100 \pm 42$ & ns \\
CD11b, \% & $100 \pm 0$ & $100 \pm 0$ & ns \\
CD11b, geoMFI & $9343 \pm 578$ & $8166 \pm 270$ & ns \\
\hline
\end{tabular}

Comparisons were done between SLE patients and healthy blood donors in regard of the frequency (\%) and amount (geometric mean fluorescence intensity (geoMFI) of positive cells) of CD88, CD62L and CD11b on $\mathrm{CD}_{10}^{+} \mathrm{CD} 16^{+} \mathrm{PMN}$. Values represent mean \pm standard error of the mean. The two-sided Mann-Whitney test was used to calculate the level of significance; ns, not significant.

study were in remission and possibly our cohort contained more patients with organ damage giving rise to the divergent results. In addition, an influence of genetic factors could not be excluded.

Corticosteroids have been reported to affect the ROS production in PMN in a cumulative dose-dependent way [30], and it is presently unclear whether this effect is due to increased disease severity. In our study, no correlation between corticosteroid dose and the amount of intracellular ROS produced was observed. The patients had relatively low doses of corticosteroids (mean $=5 \mathrm{mg}$ oral prednisone per day in treated patients) that are likely too low to affect the function of PMN. This could explain why no correlation with ROS levels was found. Moreover, other forms of immune suppressive drugs did neither seem to affect ROS production in the current setting.

Decreased neutrophil counts occur in SLE [31,32]. While this is partly due to autoantibodies, there is also evidence for direct effects on the bone marrow production of PMN. Bone marrow from SLE patients has decreased granulocyte-macrophage colony-forming units [31-33], and we show here that SLE patients have reduced numbers of newly released $\mathrm{CD} 10^{-} \mathrm{CD} 16^{\text {low }}$ neutrophils [6,7]. In agreement with earlier observations, these findings suggest an SLE-associated effect on the bone marrow with decreased release of new incompletely differentiated neutrophils. Hence, a decreased number of PMN will be found in the circulation, and with decreased numbers of PMN in the circulation, a prolonged half-life of the existing cells likely occur.

Another possibility is that the PMN phenotype in SLE patients is altered via an as-yet unidentified mechanism. The CD10 and CD16 molecules are normally stored intracellularly and can be rapidly mobilized to the cell surface upon activation [34]. Hence, an increased percentage of $\mathrm{CD} 10^{+} \mathrm{CD} 16^{+}$cells and a corresponding decrease in $\mathrm{CD} 10^{-} \mathrm{CD} 16^{\text {low }}$ cells could reflect increased activation of PMN in vivo in SLE. In addition, the percentage of C5aR was decreased, indicating that PMN are activated in peripheral blood [35,36]. However, no increase in CD11b expression and corresponding decrease in CD62L were observed on SLE-PMN. Taken together, the observed altered PMN phenotype could be due to prolonged turnover of SLE-PMN in the circulation that gives rise to functional changes such as decreased ROS production and an atypical expression of surface markers.

\section{Conclusions}

Our study shows an association between low ROS formation and disease severity in SLE. This is consistent with findings in other autoimmune disease, suggesting that a decrease in NADPH complex-mediated ROS production is a risk factor in autoimmunity. The phenotype observed in SLE-PMN could be due to aberrant production of leukocytes in the bone marrow and/or in vivo activation in the circulation. Future studies will illuminate the role of ROS formation and PMN in SLE and autoimmunity.

\section{Abbreviations}

E. coli: Escherichia coli; NADPH: nicotinamide adenine dinucleotide phosphate-oxidase; NETs: Neutrophil extracellular traps; PMA: Phorbol 12-myristate 13-acetate; PMN: polymorphonuclear leukocytes; ROS: reactive oxygen species; SLE: systemic lupus erythematosus; SLEDAI-2 K: systemic lupus erythematosus disease activity index 2000; SLE-PMN: PMN from SLE patients; SLICC/ACR-DI: Systemic Lupus International Collaborative Clinics/ American College of Rheumatology damage index.

\section{Competing interests}

The authors declare that they have no competing interests.

\section{Authors' contributions}

$\AA \mathrm{P}, \mathrm{BG}$ and $\AA \mathrm{J}$ did the laboratory work. $\mathrm{BG}$ and $\mathrm{AB}$ gathered all clinical data. $\mathrm{AB}, \mathrm{TH}, \mathrm{MH}, \mathrm{SW}, \mathrm{BG}$ and $\AA \mathrm{J}$ contributed to the design of the study and wrote the manuscript. All authors read and approved the final manuscript.

\section{Acknowledgements}

This work was supported by grants from Alfred Österlund's Foundation, The Crafoord Foundation, Greta and Johan Kock's Foundation, King Gustaf V's 80th Birthday Foundation, Lund University Hospital, the Swedish Rheumatism Association, the Swedish Research council (X65X-15152) and the Foundation of the National Board of Health and Welfare.

\section{Author details}

${ }^{1}$ Department of Clinical Sciences, Section of Rheumatology, Lund University and Skåne University Hospital, 22185 Lund, Sweden. 'Department of Nephrology, Clinical Sciences in Lund, Lund University, BMC B13, 22184 Lund, Sweden. ${ }^{3}$ Department of Haematology, Lund University, BMC B13, 221 84 Lund, Sweden. ${ }^{4}$ Department of Laboratory Medicine Lund. Section of Microbiology, Immunology and Glycobiology, Lund University, Lund, Sweden. ${ }^{5}$ Clinical Immunology and Transfusion Medicine, University and Regional Laboratories Region Skåne, 22185 Lund, Sweden.

Received: 3 December 2013 Accepted: 29 May 2014

Published: 5 June 2014

\section{References}

1. Bengtsson A, Nezlin R, Shoenfeld Y, Sturfelt G: DNA levels in circulating immune complexes decrease at severe SLE flares-correlation with complement component C1q. J Autoimmun 1999, 13:111-119.

2. Herrmann M, Voll RE, Zoller OM, Hagenhofer M, Ponner BB, Kalden JR: Impaired phagocytosis of apoptotic cell material by monocyte-derived macrophages from patients with systemic lupus erythematosus. Arthritis Rheum 1998, 41:1241-1250. 
3. Gaipl US, Voll RE, Sheriff A, Franz S, Kalden JR, Herrmann M: Impaired clearance of dying cells in systemic lupus erythematosus. Autoimmun Rev 2005, 4:189-194

4. Hakkim A, Furnrohr BG, Amann K, Laube B, Abed UA, Brinkmann V, Herrmann M, Voll RE, Zychlinsky A: Impairment of neutrophil extracellular trap degradation is associated with lupus nephritis. Proc Natl Acad Sci USA 2010, 107:9813-9818.

5. Leffler J, Martin M, Gullstrand B, Tyden H, Lood C, Truedsson L, Bengtsson AA, Blom AM: Neutrophil extracellular traps that are not degraded in systemic lupus erythematosus activate complement exacerbating the disease. J Immunol 2012, 188:3522-3531.

6. Kaneko T, Stearns-Kurosawa DJ, Taylor F Jr, Twigg M, Osaki K, Kinasewitz GT, Peer G, Kurosawa S: Reduced neutrophil CD10 expression in nonhuman primates and humans after in vivo challenge with $\mathrm{E}$. coli or lipopolysaccharide. Shock 2003, 20:130-137.

7. Orr Y, Taylor JM, Bannon PG, Geczy C, Kritharides L: Circulating CD10-/ CD16low neutrophils provide a quantitative index of active bone marrow neutrophil release. Br J Haematol 2005, 131:508-519.

8. Jonsson F, Mancardi DA, Albanesi M, Bruhns P: Neutrophils in local and systemic antibody-dependent inflammatory and anaphylactic reactions. J Leukoc Biol 2013, 94:643-656.

9. Rosetti F, Tsuboi N, Chen K, Nishi H, Ernandez T, Sethi S, Croce K, Stavrakis G, Alcocer-Varela J, Gomez-Martin D, van Rooijen N, Kyttaris VC, Lichtman AH, Tsokos GC, Mayadas TN: Human lupus serum induces neutrophilmediated organ damage in mice that is enabled by Mac-1 deficiency. J Immunol 2012, 189:3714-3723.

10. Furebring $M$, Hakansson L, Venge $P$, Sjolin J: Differential expression of the C5a receptor and complement receptors 1 and 3 after LPS stimulation of neutrophils and monocytes. Scand J Immunol 2004, 60:494-499.

11. Smith CW: Leukocyte-endothelial cell interactions. Semin Hematol 1993, 30:45-53. discussion 54-45.

12. Bedard K, Krause $\mathrm{KH}$ : The NOX family of ROS-generating NADPH oxidases: physiology and pathophysiology. Physiol Rev 2007, 87:245-313.

13. Hansson M, Hermodsson S, Brune M, Mellqvist UH, Naredi P, Betten A Gehlsen KR, Hellstrand K: Histamine protects T cells and natural killer cells against oxidative stress. J Interferon Cytokine Res 1999, 19:1135-1144.

14. Hansson M, Romero A, Thoren F, Hermodsson S, Hellstrand K: Activation of cytotoxic lymphocytes by interferon-alpha: role of oxygen radical-producing mononuclear phagocytes. J Leukoc Biol 2004, 76:1207-1213.

15. Holmdahl R, Sareila O, Pizzolla A, Winter S, Hagert C, Jaakkola N, Kelkka T, Olsson LM, Wing K, Backdahl L: Hydrogen peroxide as an immunological transmitter regulating autoreactive T cells. Antioxid Redox Signal 2013, 18:1463-1474

16. Mellqvist UH, Hansson M, Brune M, Dahlgren C, Hermodsson S, Hellstrand K. Natural killer cell dysfunction and apoptosis induced by chronic myelogenous leukemia cells: role of reactive oxygen species and regulation by histamine. Blood 2000, 96:1961-1968.

17. Gateva V, Sandling JK, Hom G, Taylor KE, Chung SA, Sun X, Ortmann W, Kosoy R, Ferreira RC, Nordmark G, Gunnarsson I, Svenungsson E, Padyukov L, Sturfelt G, Jönsen A, Bengtsson AA, Rantapää-Dahlqvist S, Baechler EC, Brown EE, Alarcón GS, Edberg JC, Ramsey-Goldman R, McGwin G Jr, Reveille JD, Vilá LM, Kimberly RP, Manzi S, Petri MA, Lee A, Gregersen PK, et al: A large-scale replication study identifies TNIP1, PRDM1, JAZF1, UHRF1BP1 and IL10 as risk loci for systemic lupus erythematosus. Nat Genet 2009, 41:1228-1233.

18. Johnston RB: Clinical aspects of chronic granulomatus disease. Curr Opin Hematol 2001, 8:17-22

19. Segal BH, Leto TL, Gallin Jl, Malech HL, Holland SM: Genetic, biochemical, and clinical features of chronic granulomatous disease. Medicine (Baltimore) 2000, 79:170-200.

20. Tan EM, Cohen AS, Fries JF, Masi AT, McShane DJ, Rothfield NF, Schaller JG Talal N, Winchester RJ: The 1982 revised criteria for the classification of systemic lupus erythematosus. Arthritis Rheum 1982, 25:1271-1277.

21. Gladman DD, Ibanez D, Urowitz MB: Systemic lupus erythematosus disease activity index 2000. J Rheumatol 2002, 29:288-291.

22. Gladman D, Ginzler E, Goldsmith C, Fortin P, Liang M, Urowitz M, Bacon P, Bombardieri S, Hanly J, Hay E, Isenberg D, Jones J, Kalunian K, Maddison P, Nived O, Petri M, Richter M, Sanchez-Guerrero J, Snaith M, Sturfelt G, Symmons D, Zoma A: The development and initial validation of the systemic lupus international collaborating clinics/American college of rheumatology damage index for systemic lupus erythematosus. Arthritis Rheum 1996, 39:363-369.

23. Perazzio SF, Salomao R, Silva NP, Andrade LE: Increased neutrophil oxidative burst metabolism in systemic lupus erythematosus. Lupus 2012, 21:1543-1551

24. Eksioglu-Demiralp E, Direskeneli H, Kibaroglu A, Yavuz S, Ergun T, Akoglu T: Neutrophil activation in Behcet's disease. Clin Exp Rheumatol 2001 19:S19-S24.

25. Mossberg N, Andersen O, Nilsson S, Dahlgren C, Hellstrand K, Lindh M, Svedhem A, Bergstrom T, Movitz C: Oxygen radical production and severity of the Guillain-Barre syndrome. J Neuroimmuno/ 2007, 192:186-191.

26. Mossberg N, Movitz C, Hellstrand K, Bergstrom T, Nilsson S, Andersen O: Oxygen radical production in leukocytes and disease severity in multiple sclerosis. J Neuroimmunol 2009, 213:131-134.

27. El-Benna J, Dang PM, Gougerot-Pocidalo MA: Priming of the neutrophil NADPH oxidase activation: role of $\mathrm{p} 47$ phox phosphorylation and NOX2 mobilization to the plasma membrane. Semin Immunopathol 2008 30:279-289.

28. Alves CMM-MC, Carvalho IF, Lucisano Valim YM: Application of the chemiluminescence systems to evaluate the role of Fcgamma and complement receptors in stimulating the oxidative burst in neutrophils. Talanta 2003, 60:601-608.

29. Shah D, Aggarwal A, Bhatnagar A, Kiran R, Wanchu A: Association between T lymphocyte sub-sets apoptosis and peripheral blood mononuclear cells oxidative stress in systemic lupus erythematosus. Free Radic Res 2011, 45:559-567.

30. Fukushima K, Ando M, Ito K, Suga M, Araki S: Stimulus- and cumulative dose-dependent inhibition of O2- production by polymorphonuclear leukocytes of patients receiving corticosteroids. J Clin Lab Immunol 1990, 33:117-123.

31. Nossent JC, Swaak AJ: Prevalence and significance of haematological abnormalities in patients with systemic lupus erythematosus. Q J Med 1991, 80:605-612.

32. Hepburn AL, Narat S, Mason JC: The management of peripheral blood cytopenias in systemic lupus erythematosus. Rheumatology (Oxford) 2010, 49:2243-2254

33. Papadaki HA, Boumpas DT, Gibson FM, Jayne DR, Axford JS, Gordon-Smith EC, Marsh JC, Eliopoulos GD: Increased apoptosis of bone marrow CD34 $(+)$ cells and impaired function of bone marrow stromal cells in patients with systemic lupus erythematosus. Br J Haematol 2001, 115:167-174.

34. Elghetany MT: Surface antigen changes during normal neutrophilic development: a critical review. Blood Cells Mol Dis 2002, 28:260-274.

35. Furebring $M$, Hakansson LD, Venge $P$, Nilsson $B$, Sjolin J: Expression of the C5a receptor (CD88) on granulocytes and monocytes in patients with severe sepsis. Crit Care 2002, 6:363-370

36. Furebring $M$, Hakansson $L$, Venge $P$, Sjolin J: $C 5 a$, interleukin- 8 and tumour necrosis factor-alpha-induced changes in granulocyte and monocyte expression of complement receptors in whole blood and on isolated leukocytes. Scand J Immunol 2006, 63:208-216.

\section{doi:10.1186/ar4575}

Cite this article as: Bengtsson et al:: Low production of reactive oxygen species in granulocytes is associated with organ damage in systemic lupus erythematosus. Arthritis Research \& Therapy 2014 16:R120.

\section{Submit your next manuscript to BioMed Central and take full advantage of:}

- Convenient online submission

- Thorough peer review

- No space constraints or color figure charges

- Immediate publication on acceptance

- Inclusion in PubMed, CAS, Scopus and Google Scholar

- Research which is freely available for redistribution 